\title{
K4D
}

\section{Lessons learned from education initiatives implemented during the first wave of COVID-19: A literature review}

Kate Sims

Education Development Trust

December 2021 


\section{About this report}

The K4D Emerging Issues Report series highlights research and emerging evidence to policymakers to help inform policies that are more resilient to the future. K4D staff researchers work with thematic experts and the UK Government's Foreign, Commonwealth \& Development Office (FCDO) to identify where new or emerging research can inform and influence policy.

This literature review is based on 4.5 days of desk-based research, carried out during August 2021.

K4D services are provided by a consortium of leading organisations working in international development, led by the Institute of Development Studies (IDS), with the Education Development Trust, Itad, University of Leeds Nuffield Centre for International Health and Development, Liverpool School of Tropical Medicine (LSTM), University of Birmingham International Development Department (IDD), and the University of Manchester Humanitarian and Conflict Response Institute (HCRI).

For any enquiries, please contact helpdesk@k4d.info.

\section{Acknowledgements}

We would like to thank Astrid Korin and Leanne Cameron (Education Development Trust), who provided advice and guidance on the development of this literature review and served as external expert reviewers.

Finally, we would like to thank Barbara Cheney, who copy-edited this literature review.

\section{Suggested citation}

Sims, K. (2021). Lessons learned from education initiatives implemented during the first wave of COVID-19: A literature review. K4D Emerging Issues Report No. 44. Brighton, UK: Institute of Development Studies. DOI: 10.19088/K4D.2021.134

\section{Copyright}

This report was prepared for the UK Government's Foreign, Commonwealth \& Development Office (FCDO) and its partners in support of pro-poor programmes. Except where otherwise stated, it is licensed for non-commercial purposes under the terms of the Open Government Licence v3.0. K4D cannot be held responsible for errors or any consequences arising from the use of information contained in this report. Any views and opinions expressed do not necessarily reflect those of FCDO, K4D or any other contributing organisation.

(c) Crown copyright 2021.

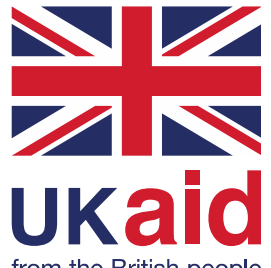




\section{Contents}

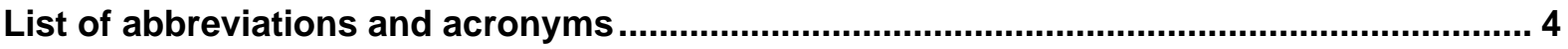

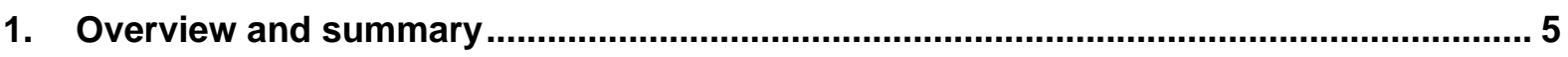

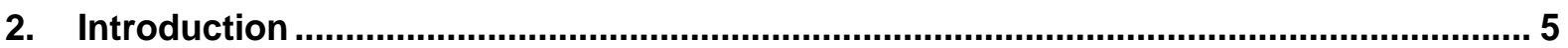

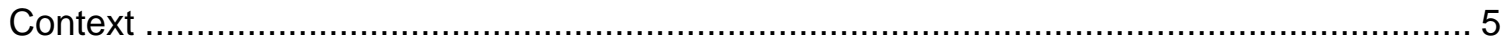

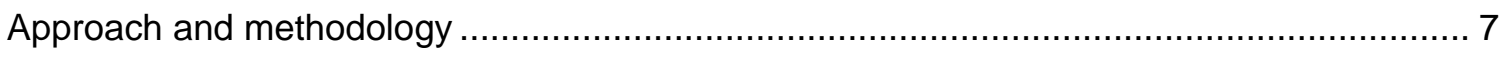

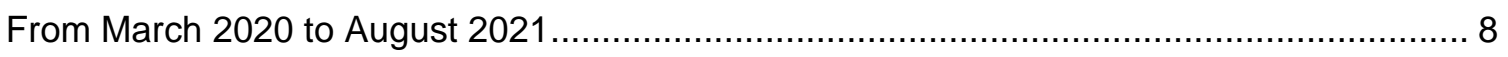

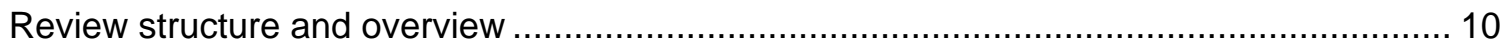

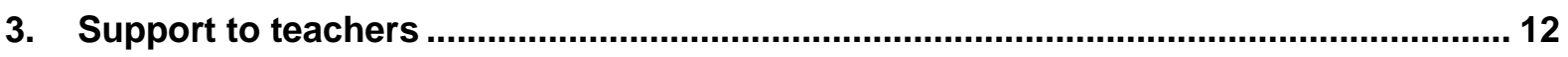

Supporting teachers to continue teaching during school closures ..................................... 12

The role of teachers in relation to disadvantaged groups' access and engagement with

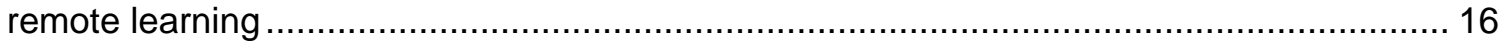

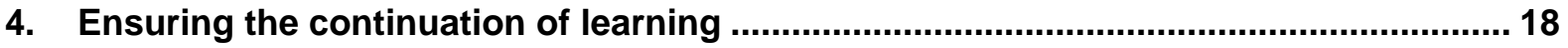

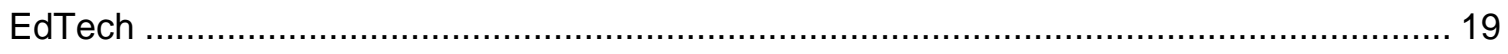

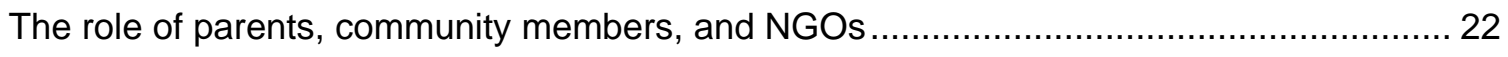

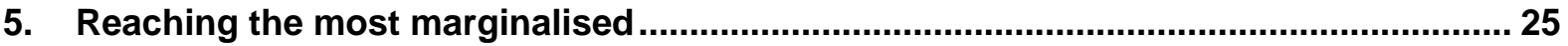

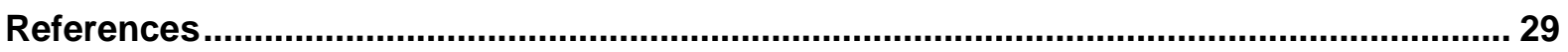

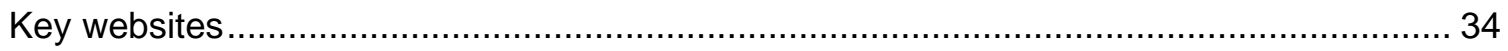




\section{List of abbreviations and acronyms}

\begin{tabular}{ll} 
ARM & Accessible Reading Materials \\
CHV & community health volunteer \\
DRC & Democratic Republic of the Congo \\
EdTech & education technology \\
FCDO & Foreign, Commonwealth \& Development Office \\
GBV & gender-based violence \\
GPE & Global Partnership for Education \\
ICT & information and communications technology \\
JRS & Jesuit Refugee Service \\
LMICs & low- and middle-income countries \\
MEL & monitoring, evaluation, and learning \\
NFE & non-formal education \\
NGO & non-government organisation \\
NTC & National Teachers' Colleges \\
ODA & Official Development Assistance \\
SENSA & Sindh Education Non-State Actors \\
SESIL & Strengthening Education Systems for Improved Learning \\
SMS & Short Message Service \\
UDL & Universal Design for Learning \\
UNICEF & United Nations Children's Emergency Fund \\
UNESCO & United Nations Educational, Scientific and Cultural Organization \\
USAID & United States Agency for International Development \\
\hline
\end{tabular}




\section{Overview and summary}

It is important to assume that the learning crisis caused by COVID-19 is not over. As highlighted by 2021 school closures in response to the Delta variant, lessons learned from school closures in 2020 are required and applicable. There is therefore a need for reflection and a consolidation of lessons learned to protect education outcomes. Lessons include the need for parental engagement and support, the mobilisation of community actors, and inclusive and accessible remote learning approaches (Kapur, 2020, p. 38).

This literature review seeks to better understand what worked and what did not work in education interventions during the first wave of COVID-19, in order to support planning on current and future school closures and/or disruptions to education systems. It focuses on three key areas:

1. Support to teachers to continue teaching during school closures, and the role of teachers in supporting marginalised learners;

2. Approaches to ensure the continuation of learning; and

3. Approaches to reach the most marginalised learners.

\section{Introduction}

\section{Context}

The first wave of the COVID-19 pandemic disrupted education for approximately 1.6 billion children (and $85 \%$ of learners) across 180 countries during the peak of school closures in April 2020 (Mcclain-Nhlapo et al., 2020; World Bank, 2021a, 2021b). On average across the world, schools across all four stages of education were closed for 79 days; 53 days on average in high-income countries, and 115 days on average across lower-middle-income countries - see graph 'Mean of instruction days lost by level of education and income group in 2020' (UNESCO et al., 2021, p. 14)

(http://uis.unesco.org/sites/default/files/documents/lessons_on_education_recovery.pdf) ${ }^{1}$.

Emerging evidence suggests that learners affected by school closures have experienced "an absolute reduction in learning levels or slower progress than expected in a typical year" (UNESCO et al., 2021, p. 5).

This is reinforced by recent research across 46 countries by Save the Children, which found that over two thirds of learners did not have any contact with their teachers during school closures, and over a quarter of learners did not have access to learning materials (Gordon, 2020). There has been a disproportionate impact on vulnerable and marginalised learners, confounded by the digital divide and access to resources, their geographical location, gender, and socioeconomic status, especially in low- and middle-income countries (LMICs) (Hossain, 2021). In Ethiopia, Kenya, Liberia, Tanzania, and Uganda, it has been estimated that learners have lost between half and over one year's worth of learning, defined as learning deterioration and opportunity cost (Angrist, de Barros et al., 2020).

${ }^{1} \mathrm{~K} 4 \mathrm{D}$ has approached UNESCO for approval but received no response. 
At the beginning of July 2021, the majority of schools had reopened following the first and second waves of COVID-19, and there were 14 country-wide school closures, which affected over 118 million learners (UNESCO, n.d.).

As a result, the focus of donors and ministries of education has rightly shifted from disruption to recovery, through remedial programmes, catch-up classes, and a drive for children to return to school. Despite the mass COVID-19 vaccination programmes implemented in highincome countries since December 2020, only $19 \%$ of low-income countries are currently vaccinating or have already vaccinated teachers as a priority group, as outlined in the graphic 'Prioritisation status for teacher vaccination'

(https://www.covideducationrecovery.global/stories/2021-09-23-gert-data-points/) ${ }^{2}$ (Johns Hopkins University et al., 2021). This is contributing to a "two-track recovery from the COVID-19 pandemic", further compounded by the Delta and other emerging variants, which is forcing some countries to reinstate public health and social restrictions, including the closure of schools (Johns Hopkins University et al., 2021). In line with FCDO planning for medium-case scenarios, the "cyclical" nature of the COVID-19 virus will likely result in public health measures being periodically reintroduced or relaxed as infection rates rise or fall (Kapur, 2020, p. 38).

It is important to assume that the learning crisis caused by COVID-19 is not over as ongoing school closures will continue to lead to lost learning, caused by time out of school and learning regression (Page et al., 2021).

According to Kaffenberger (2021), a three-month period of school closures could result in the loss of over one full year's worth of learning by the time that children currently in grade 3 reach grade 10. Angrist, de Barros et al. (2020) estimate, however, that learning losses in similar circumstances could amount to 2.8 years of learning losses by grade 10 .

For example, the medium-term effects of the earthquake that occurred in northern Pakistan in 2005 included a difference of approximately 1.5 school grades in children living within a $10 \mathrm{~km}$ radius of the fault lines, compared to those living $40 \mathrm{~km}$ away (Andrabi et al., 2020).

The COVID-19 pandemic and associated school closures are likely to exacerbate the factors that have contributed to the already existing learning crisis, which include low learning outcomes, limited teacher skills and motivation, and national policies to ensure learning for all children, and bureaucratic structures combined with poor governance and management that undermine teaching quality (Banerji, 2020; World Bank, 2018). As a result, when children return to school, they will be behind the place in the curriculum that would normally be expected, and will continue to fall behind without specific measures to remediate learning (Angrist, de Barros et al., 2020; Kaffenberger, 2021). This is highlighted in Figure 1, which also demonstrates the importance of remedial activities to address lost learning and reorientation activities. The effects will be further compounded for marginalised learners, including those with low levels of literacy, and those that experienced psychological or socioemotional stress or trauma during the periods of school closure (Page et al., 2021).

${ }^{2}$ K4D has approached John Hopkins University for approval to use this graphic but received no response. 
Figure 1: Children in school but not learning for different strategies to mitigate the shock of COVID-19, based on half a year's initial learning loss for children in grade 1

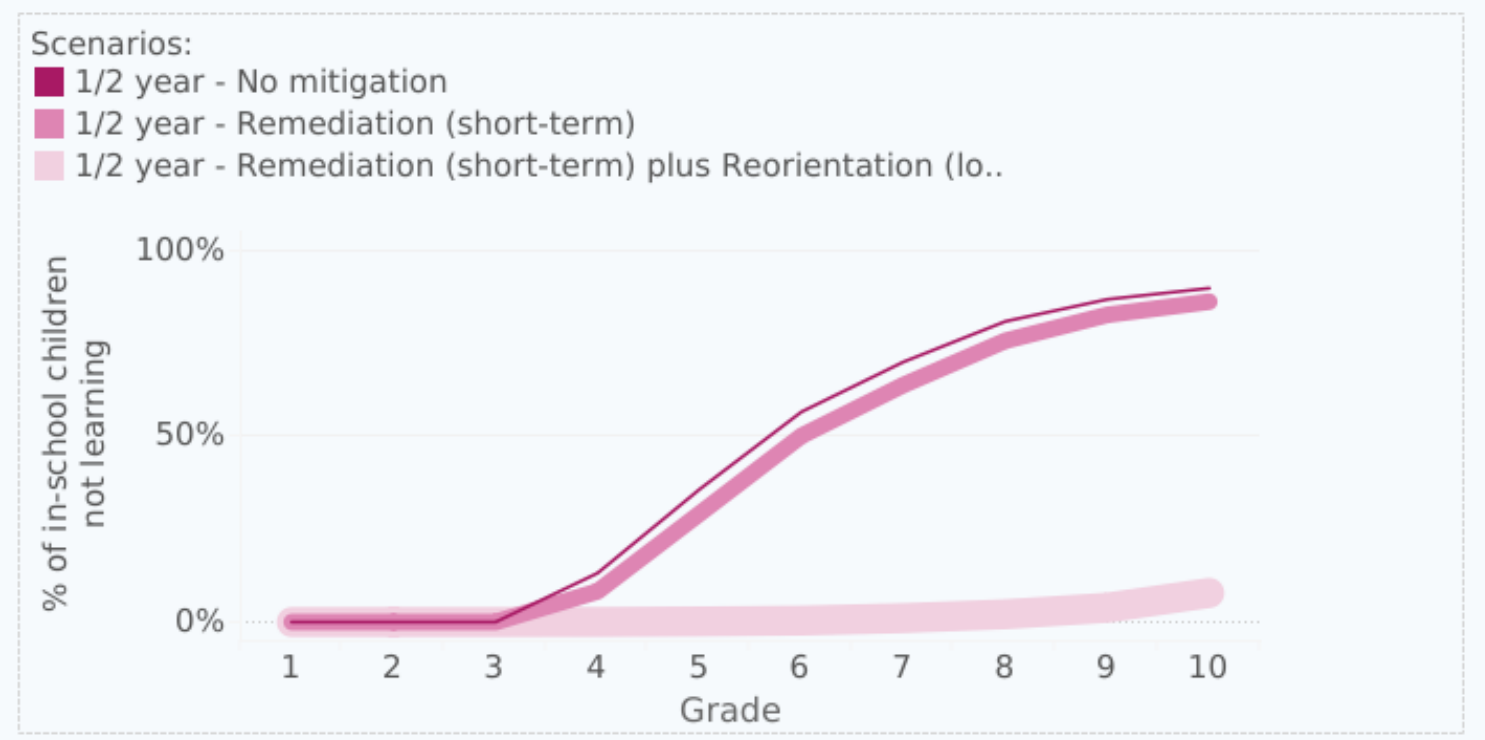

Source: Belafi \& Kaffenberger (2020). Reproduced with permission.

Foundational skills and learning have been widely recognised as a key remediation strategy to mitigate the longer-term impacts of the pandemic on learning outcomes, as well as addressing the pre-pandemic learning crisis (Angrist, de Barros et al., 2020; Kaffenberger, 2021; Page et al., 2021). The use of formative assessment is critical to provide ongoing feedback on learners' progress, and enable teachers to ensure that their teaching best supports learners (Angrist, de Barros et al., 2020; Jenkins \& Banerji, 2021; Kaffenberger, 2021). These elements are not explicitly addressed within this study, largely because foundational skills and assessment were not explicit research questions. However, foundational skills and effective assessment, and supporting teachers to deliver these and supporting children's learning needs, should be considered as important principles for success going forward for each of the lessons identified.

Supporting children to return to school must also be acknowledged as a critical issue in the COVID-19 recovery period, although it is not a research question for this study. In Kenya, for example, the Population Council estimates that $16 \%$ of girls and $8 \%$ of boys in Nairobi, Kisumu, Kilifi, and Wajir did not return to school at the beginning of 2021 (Mwabe et al., 2021). This was primarily due to the affordability of school fees, though other causes include unplanned pregnancies for girls, and entering the labour market for boys.

\section{Approach and methodology}

This study seeks to better understand what worked and what did not work in education interventions during the first wave of COVID-19, to support planning on current and future school closures and/or disruptions to education systems.

The research question for the study is: "What can we learn from policy responses, interventions, and initiatives adopted in response to the first wave of COVID-19 and subsequent school closures in LMICs to inform continuing and future disruptions to schools caused by future waves of the virus?" The research sub-questions are: 
1. What have we learnt about what works to support teachers to continue teaching during closures (e.g. guidance, financial stipends, additional training, peer support and learning, etc.)?

2. What have we learnt about the role of teachers in relation to marginalised learners' access and engagement with remote learning?

3. Online platforms and television have been the most used remote learning methods in national responses, but $75 \%$ of learners in low-income countries do not have access to online learning and $31 \%$ do not have access to television or radio. What have we learnt about no-tech, low-tech, and high-tech models for continued learning?

4. What have we learnt about the approaches needed to reach the most marginalised, including girls?

This literature review draws on a variety of publications published since September 2020, including academic studies, publicly available programme reports, and grey literature to explore these questions. Where possible, the review has not drawn on literature that purely focuses on the impact of COVID-19, nor those materials which only present recommendations for policymakers and education actors without explicitly drawing on evidence from interventions adopted in response to the pandemic. The focus of this study is on the period of school closures in LMICs, rather than exploring lessons learned from the learning recovery phase. It should be noted that 4.5 days were allocated to this literature review, therefore this should not be considered as a comprehensive literature review.

\section{From March 2020 to August 2021}

In March 2020, K4D published a rapid literature review on evidence of efforts to mitigate the negative educational impacts of disease outbreaks, drawing primarily on evidence from the Ebola outbreak in West Africa (Hallgarten, 2020). Many of the secondary impacts of disease outbreaks that were identified in that document have since been realised throughout the period of school closures due to COVID-19 (Hallgarten, 2020, p. 3; Gordon, 2020; UNESCO et al., 2021). Namely, a reduction in availability of education services (through school closures and a lack of remote learning materials), a reduction in access to education services (through restriction of movements due to social distancing and reduced financial income), and a lack of quality appropriate education (through a lack of teacher training during crisis) (Hallgarten, 2020, p. 3).

Table 1 outlines the key messages within the Hallgarten (2020) review, focusing specifically on support to teachers, continuation of learning, and reaching the most marginalised. Generally speaking, the majority of these messages remain true when reviewing the learning from the first wave of COVID-19. In some cases, however, evidence from the past year provides further nuance and detail. 
Key area of

intervention

\section{Insights from Hallgarten (2020) review}

Teachers' roles were diverted towards disease control and social mobilisation activities, including psycho-social support.

Support to teachers

Limited support was provided to teachers in terms of training and professional development, beyond disease-related training.

Continuity of learning Lower-tech solutions were prominent in supporting the continuity of learning, including radio.

There was stronger evidence of informal learning programmes (including adaptations of existing programmes), including those that provide psycho-social support.

There was limited support to parents to improve the educational or psycho-social support they could provide to their children during school closures.

Organisations and actors that have existing relationships and established trust with local communities and authorities can create results to support the continuity of learning, with flexibility from donors and adaptiveness from programme implementers.

\section{Reaching the most marginalised}

School closures have disproportionate negative impacts on the learning, safety, and wellbeing of the most vulnerable children in the poorest families.

Female learners bear a greater negative cost of disease outbreaks, with a heightened likelihood of being subject to sexual exploitation, sexual abuse, teenage pregnancy, and early marriage.

The review found only one example of an approach to mitigate the educational or child protection impacts on female learners. 


\title{
The Hallgarten (2020) review highlighted the lack of coordination and integration of education within the broader response to crises; however, some of the interventions adopted in response to Covid-19 seem to have adopted a different approach with strong elements of alignment and coordination.
}

\begin{abstract}
A key feature of the education sector's response to school closures and COVID-19 was the mobilisation and coordination of community actors to maintain contact with learners during that period, which is in marked contrast with what occurred in West Africa during the Ebola outbreaks, as reported by Hallgarten (2020). This was particularly the case in work to support the most marginalised learners, including children with disabilities and adolescent girls, where multisectoral and multilevel coordination and collaboration seemed critical to the success of these interventions.
\end{abstract}

In addition, although not the focus of this review, multisectoral and multilevel coordination and collaboration between ministries, donor organisations, and implementing partners has been a key feature of school reopening strategies, with the focus on supporting marginalised children (both those that were marginalised before and because of COVID-19) and "building back better" (UNICEF, 2021b, 2021c, 2021e, 2021f, 2021g). This includes working with health, food and agriculture, social services, violence against women and girls, and safeguarding sectors.

\section{Review structure and overview}

The three sections that follow generally reflect the four research sub-questions outlined above. Section 3 addresses the first and second research questions, which seek to understand lessons learned from supporting teachers to continue teaching during school closures, and the role of teachers in supporting marginalised learners' access to remote learning initiatives. Teachers were required to adopt remote learning approaches in a number of countries; however, the support to teachers was generally inconsistent, determined in part by access to relevant devices (i.e. mobile phones to make telephone calls and send SMSs, and internet-enabled devices including computers and smartphones) and learning materials (International Task Force on Teachers for Education 2030, 2021). Features of effective remote professional development support to teachers replicated the key principles of face-to-face provision. This included peer support and coaching, facilitated through a variety of EdTech approaches, including online collaboration platforms through to SMS and WhatsApp, and self-directed study. However, the review only identified a small number of interventions that used these forums to provide holistic training, including subjectspecific knowledge, pedagogical skills, and online pedagogy.

Although some teachers were provided with guidance on disease control, psycho-social support and training seemed to be a key omission in the general education response to COVID-19, evidenced by a number of publications highlighting this as a priority need (McAleavy et al., 2021; Save the Children, 2020; World Bank, 2021a, 2021b). This further validates findings in the Hallgarten (2020) review, which also calls for these areas to be prioritised in sensitising and training teachers.

A large number of teachers were required to make daily contact with their students and/or their parents during the period of school closures (International Task Force on Teachers for 
Education 2030, 2021). Despite this effort, the limited evidence identified limited examples of teachers' specific support to marginalised learners. The exception to this, however, was the role of non-state education providers who continued to support marginalised learners excluded from government-provided education.

Section 4 reviews approaches to support the continuation of learning, drawing on the role of EdTech, and parental and community support and engagement. Evidence on the effectiveness of remote learning strategies is inconsistent and limited in low- and middleincome contexts, although there are some areas of promise. Even though the majority of countries implemented remote learning strategies in response to COVID-19 and school closures, there have been widespread challenges in implementation. Access to remote learning approaches has been confounded by a variety of factors, including infrastructure, socioeconomic status, location, and gender (Hossain, 2021; Yorke et al., 2021).

Section 4 also highlights the importance of a no-tech safety net, which could be provided by parents, teachers, and community-based education actors. There is considerable opportunity in mixed models of remote and face-to-face education provision, and combining high-tech with low-tech and no-tech (van Cappelle et al., 2021). Where remote learning interventions were successfully implemented, there was strong involvement, support from, and coordination with community-based actors, including district officials and middle-tier professionals. Although this section echoes the Hallgarten (2020) review in many ways, this review identified a number of approaches that proactively supported and encouraged parents' engagement in their children's learning during the pandemic, although this was not widespread.

Section 5 reviews the literature and research on approaches needed to reach the most marginalised learners, including girls. As with Section 4, it identifies the importance of lowtech and no-tech approaches combined with support and contact from education actors as a key feature of success. However, research and literature that has been published since September 2020 reflect sentiments in the Hallgarten (2020) review, which highlights the need for interventions that go beyond academic education approaches to support marginalised learners (Kapur, 2020; Mcclain-Nhlapo et al., 2020; Niemczyk et al., 2021; UNICEF, 2021a). These interventions include safeguarding, safety, wellbeing, and humanitarian support, including the provision of basic staples. 


\section{Support to teachers}

This section addresses the first and second sub-questions: "What have we learnt about what works to support teachers to continue teaching during closures (e.g. guidance, financial stipends, additional training, peer support and learning, etc.)?" and "What have we learnt about the role of teachers in relation to marginalised learners' access and engagement with remote learning?"

School leaders and teachers are critical actors in determining and overseeing school-level responses to the COVID-19 pandemic and ensuring learners' engagement with education during the period of school closure (McAleavy et al., 2021; van Cappelle et al., 2021; Yorke et al., 2021). In response to school closures, both school leaders and teachers have been required to adapt to continue teaching, and to support learners, their parents, and/or caregivers (Yorke et al., 2021).

Despite this, the limited evidence shows that the role of teachers to support remote learning and continue teaching during school closures differed significantly across the world. In some countries, notably those in Asia, teachers continued to teach during school closures (UNESCO Asia et al., 2021). In other contexts, mostly in sub-Saharan Africa, teachers were sent home after school closures and were not allocated any work to continue teaching. The factors that influenced teachers' limited involvement in remote learning included a lack of timely information and guidance, and access to electricity and communication devices (Yorke et al., 2020). There is also a general lack of research on school leaders and teachers' experiences from the pandemic (Yorke et al., 2020).

\section{Supporting teachers to continue teaching during school closures}

Findings from the International Task Force on Teachers for Education 2030 (2021) identified that in the majority of countries, teachers were required to adopt remote learning approaches during school closures. However, as indicated above, this differed from country to country. In addition, supporting teachers took various forms, and in some contexts, teachers were provided training in remote learning approaches in order to support learners. One in 10 countries reported no support for teachers, and in sub-Saharan Africa $20 \%$ of countries reported no support for teachers (International Task Force on Teachers for Education 2030, 2021 , p. 2). As demonstrated here, there was great variety in how, when, and if teachers were provided with financial support.

\section{Although some teachers received financial support to continue teaching during school closures, the results from a survey issued by EdTech Hub indicate that a large majority of educators in Africa did not receive financial support to continue teaching (EdTech Hub, 2020, p. 5).}

Furthermore, in $30 \%$ of countries in sub-Saharan Africa, contract teachers did not receive full pay during school closures (International Task Force on Teachers for Education 2030, 2021). In Bosnia and Herzegovina, San Marino, and Yemen, contract teachers stopped receiving their salaries, and in Lebanon, Vietnam, Ghana, Kenya, and Sierra Leone, their salaries were reduced. In Chad, $60 \%$ of community teachers experienced pay stalls (Mcclain-Nhlapo et al., 2020 , p. 31). In the Democratic Republic of the Congo (DRC), teachers in the east of the country have experienced pay gaps, which has led to some teachers leaving the profession, 
and a high rate of absenteeism due to teachers leaving class to withdraw their salaries from their bank (ACAPS, 2020).

In contrast, there are examples where teachers received support. In São Tomé and Príncipe and the Syrian Arab Republic, teachers received a financial supplement as well as their regular salary (International Task Force on Teachers for Education 2030, 2021). In Indonesia, teachers and lecturers were provided with an internet data quota to support remote teaching (MoECRT, 2021). However, no data were available on the impact of this approach.

In countries where teachers were provided financial and professional support, a variety of EdTech approaches (including no-tech and low-tech) were adopted to deliver professional development and to highlight key safeguarding approaches. This highlighted the importance of adopting multi-model communication and using different forms of technology for different purposes. Approaches included the creation of communities of practice and teacher learning communities, using widely used platforms like WhatsApp to maintain contact with teachers.

When schools were closed in Pakistan, many teachers started informal classes using WhatsApp, teaching themselves how to use this technology for both learning and tracking the progress of their students (Diamond, 2021). Similarly, in Bhutan, after the Ministry of Education launched e-learning and initiated the broadcasting of educational lessons on television, teachers responded by adapting their teaching through different social media channels, including WhatsApp, WeChat, and Telegram Messenger (International Task Force on Teachers for Education 2030, 2021). As these messaging services are widely used and quite simple to understand, many teachers did not require formal training for using the technology itself. These platforms allow teachers to share materials, assign tasks, and address some student questions, but they are limited in replicating the interactive communication normally found within a classroom.

For contexts where teachers and students alike have internet-capable devices and internet connectivity, more online complicated platforms, such as Zoom, Microsoft Teams, and Google Classrooms, provide a closer facsimile of the classroom experience; but for teachers who lack prior experience with online learning platforms, there are multiple challenges in using the technology. They need to learn both about using the programme itself (such as mastering the chat function, sharing materials, muting all participants who are not presenting, security and safeguarding, etc.) as well as about how to use them effectively for learning rather than just uploading normal classroom content onto the platform or simply lecturing.

In Uganda, the National Teachers' Colleges (NTC) have been working to increase the digital competence of teachers, including through support to distance teaching and learning (Enabel et al., 2020). They have developed an online general teaching methods course which outlines good practice in teacher training education. This is hosted on a one-stop open access portal which is zero-rated ${ }^{3}$ by the main network provider MTN. The platform supports communities of practice and also contains learning content for all subjects that has been

\footnotetext{
${ }^{3}$ Zero-rating is an approach where internet providers allow users to access certain websites and webpages
} without charge to them, or to their internet data plan. 
created by NTC lecturers. Particularly relevant to remote and blended learning, the portal also has an ICT guide for teaching and learning which contains a set of tutorials on the main digital tools that can be used to support teaching and learning, covering topics like creating an account, sharing resources, and creating quizzes or discussion groups. As a stopgap measure, it provides some immediate support for teachers able to shift to an online modality.

However, a recent three-year controlled experiment in South Africa, conducted prior to the outbreak of COVID-19, examined the effectiveness of face-to-face and virtual coaching and teaching to deliver professional development to teachers; the study found that face-to-face coaching was more effective than virtual coaching (Cilliers et al., 2021). Although this may not be possible in contexts where COVID-19 restrictions prevent face-to-face contact, it indicates the need to replicate key features of effective professional development in virtual environments or establish small group and socially distanced peer support groups.

Peepul, a not-for-profit organisation in India, demonstrates how remote professional development could work in practice (McAleavy et al., 2021; Peepul, n.d.). Firstly, the remote model and resources developed were based on what Peepul had learnt previously about how teachers learn best, meaning that training modules needed to be:

- Short and easily consumable;

- Accessible for teachers with limited phone data; and

- Accessible for teachers with limited (or no) experience in engaging with professional development.

Accordingly, Peepul designed mixed-media content in the form of videos, quizzes, podcasts, and readings. Teachers were also given reading or exercises to complete prior to taking each training module and were sent reflective materials to complete afterwards. To support teachers who had not previously received professional development (including remote professional development), Peepul offered an initial 10-minute tutorial in online learning. The remote training encouraged reflective, practical, and supportive interactions with trainers, mentors, and peers. It was anticipated that participation in online training alone would not ensure shifts in teacher mindsets and practices. Therefore, through creating online professional development communities through YouTube Plus, they encouraged and enabled teachers to talk about what they had learned and how to translate it into day-to-day practice. In response to COVID-19, training aimed to equip teachers with practical approaches to support and work with parents to support their children's education.

Another example of an effective online professional development approach is Comunidad Atenea, an internet-based teaching learning community and support programme for teachers in Latin America, which is based in Argentina (Comunidad Atenea, n.d.; McAleavy et al., 2021; Varkey Foundation, 2020). The site offers teaching ideas and materials, courses, and a virtual community for teachers. Since school closures began, Comunidad Atenea has registered about 100 teachers per day. Although it was originally set up for teachers in Latin America, the site and materials have been accessed by professionals in 92 countries. The site uses existing widely known platforms such as YouTube and, more recently, it has teamed up with the social media platform, TikTok, to invite the creation and sharing of audiovisual content to promote and motivate learning and offer teacher development. 
In resource-scarce contexts, there are examples of low-tech options like connecting small groups of teachers through SMS (Jordan et al., 2021), which allows teachers to continue to communicate and share their experiences and ideas. Groups like this can provide some community support for teachers working both in high-tech and low-tech scenarios and, as demonstrated later, some sense of camaraderie and informal psycho-social support.

Other publications highlight the importance of training teachers in digital pedagogy to adapt to remote learning, a gap indicated by educators in Africa (EdTech Hub, 2020; McAleavy et al., 2021).

- In Indonesia, teachers were offered support through a webinar series on remote learning pedagogies. In addition, teachers were given access to an online platform called Teacher Shares, which enabled collaboration and peer-to-peer support with other teachers and private online learning providers (MoECRT, 2021).

- In Nepal, Sierra Leone, and Vietnam, the World Bank has implemented training for teachers on digital skills and also the provision of psycho-social support to learners (World Bank, 2020).

- In Asia, the most common form of support for teachers for remote teaching was the provision of instructions on how to make use of online and audiovisual learning platforms, which was followed by the adaption of existing content.

Despite these success stories, almost one in five countries did not provide any additional support for teachers, due to a lack of either capacity or requirement (UNESCO Asia et al., 2021 , p. 23). Only a small percentage of teachers in Asia received training on remote pedagogy, and how to organise remote learning. Across these examples, too, there is a clear gap in training teachers in how to support marginalised learners: existing programmes appear to be focused on addressing technological and basic pedagogical needs, rather than expanding teachers' methodological and pedagogical toolkits to target learners with specific needs.

Protecting the mental health of teachers during school closures and ensuring that new forms of education provision do not place unhelpful strain on the workforce remain important. With remote learning during the period of school closures and mixed modalities of learning and teaching as schools reopen, dividing time between direct teaching and administrative workload appeared off balance.

EdTech has partly exacerbated teachers' workloads, requiring them to learn new skills, develop and deliver their practice in new forums, and communicate with families (McAleavy et al., 2021; World Bank, 2021a). In some contexts, teachers were required to contact learners and their parents directly to follow up on learning through telephone, SMS, and virtual groups. To highlight this, $67 \%$ of countries globally encouraged teachers to interact with their students (and their parents) through SMS and messaging apps (International Task Force on Teachers for Education 2030, 2021). Therefore, approaches to alleviate some of the constraints on teachers' time "were critical in a time when students needed not only support to catch up but to deal with socio-emotional issues" (World Bank, 2021a, p. 11).

The Inter-Agency Network for Education in Emergencies (INEE) developed guidance on psycho-social support, which targets teachers and other education professionals as one of its 
five domains (INEE, 2018; McAleavy et al., 2021). It emphasises the need for effective support and supervision for teachers including through peer-to-peer networks. Practical tools and advice for school leaders on how to support teachers (and themselves) with their psycho-social and emotional wellbeing can also be found in the Teacher Taskforce toolkit (International Task Force on Teachers for Education 2030 et al., 2020). Guiding questions help school leaders consider what they can do to support staff and how to prepare staff to provide psycho-social support to learners. Peer support for leaders, teachers, and pupils is key and counselling services should intervene where required.

Save the Children has also developed a module on teacher wellbeing as part of their Safe Schools teacher professional development manual (Save the Children, 2020). The module looks at identifying and managing stress and how this influences teacher and student wellbeing. It aims to help teachers to develop personal strategies and draw on the support of others to combat stress.

\section{The role of teachers in relation to disadvantaged groups' access and engagement with remote learning}

Across the literature, the role of teachers in supporting marginalised groups' access and engagement with remote learning appears inconsistent. However, this may be because of the strong influence and impact that other community-based actors or programme teams had on supporting these groups, in terms of delivering child protection, maintaining learners' contact with education, and supporting the transition back to school (see Section 5). As was introduced in the previous subsection, the support to teachers to engage marginalised learners in remote learning approaches seemed limited and inconsistent.

Across the globe, over $20 \%$ of teachers surveyed by the World Bank felt that they did not have the support needed to help students with disabilities throughout the period of school closures (Mcclain-Nhlapo et al., 2020, p. 29). Only $16 \%$ of teachers felt that they did have the necessary support to help children with disabilities.

Interestingly, in the same survey, only $5 \%$ of teachers highlighted the need for professional development to help them support children with disabilities to engage with remote learning. The main challenges that were highlighted included availability of devices, lack of support from parents, lack of individual support for children with disabilities, and internet availability (Mcclain-Nhlapo et al., 2020, p. 31). It could therefore be suggested that teachers' support to children with disabilities during school closures should be complemented by blended inclusive approaches, including individualised face-to-face support.

With those gaps, the support of marginalised learners during the pandemic period has instead been taken up by community and non-state actors.

In Pakistan, professional development support to teachers within the non-formal education (NFE) system has supported hard-to-reach children that have fallen outside of government education provision (Rahman et al., 2021). This highlights the importance of non-state actors in supporting the continuity of education for marginalised learners.

NFE teachers were offered professional development support through an online platform, which included specific training on subject matter knowledge, pedagogical skills, and online 
training methods (Rahman et al., 2021). The professional development programme was both synchronous and asynchronous, to allow for some self-directed learning. The online format of the live training on WhatsApp reportedly increased attendance and participant responsiveness, as participants were able to use the chat function to post questions and respond to tasks. In addition, trainers were able to subtly contact teachers who were not responding through the same chat function.

The online platform also hosted learning materials for students, and SMSs were sent to raise awareness of their availability, as well as to engage learners through receiving numerous "interesting facts and brain teasers" (Rahman et al., 2021, p. 11). All materials were available in Urdu and Sindhi. In addition, the platform was used to share health guidance and wellbeing tips on how to cope with stress.

Findings from a questionnaire issued to the NFE teachers indicate that the online platform, compared to traditional NFE textbooks used by teachers and students, was easier to use, more interesting for children, and more effective in remote learning contexts (Rahman et al., 2021, p. 26).

However, a key barrier to this approach was access to technology, including gendered access.

One school near Bogotá, Colombia, demonstrated the importance of the roles of school leaders and teachers in supporting learners with disabilities. However, their support was localised and seemed to be driven by their own initiative, implying that the impact was limited and lacked coordination with education authorities. This was supported by recent research which concluded that there were significant gaps between the Government of Colombia's policy on supporting learners with disabilities and their unmet needs during the period of the pandemic (Laverde, 2021).

After schools were closed in response to COVID-19, the Jose de San Martín Commercial Technical School in Bogotá located learners with disabilities to provide support and maintain contact during the period of school closure, and issued a survey to identify their needs (Laverde, 2021). In response, the school distributed tablets with Google Suite and other applications pre-loaded, and SIM cards with an internet allowance, to the learners with disabilities. The school trained parents on how to operate the tablets, which alleviated some pressure on teachers' time. 


\section{Ensuring the continuation of learning}

This section addresses the fourth research sub-question: "What have we learnt about notech, low-tech, and high-tech models for continued learning?"

Globally, evidence on effective remote learning strategies is inconsistent, and challenges have been experienced by governments and donors in "implementing even the most basic measures to support the continued learning of students" (Yorke et al., 2021, p. 190).

Generally, this is due to infrastructure and access to resources, which are influenced by learners' socioeconomic status, geographic location, and gender (Hossain, 2021; Yorke et al., 2021).

The findings from this section, and on what works for the continuation of learning during school closures, are summarised in Figure 2. This highlights the opportunity afforded by mixed models of remote and face-to-face education provision, and combining high-tech with low-tech and no-tech (van Cappelle et al., 2021). Where remote learning interventions were successfully implemented, there was strong involvement, support from, and coordination with community-based actors, including district officials and middle-tier professionals.

Figure 2: Mixed modalities for effective remote learning

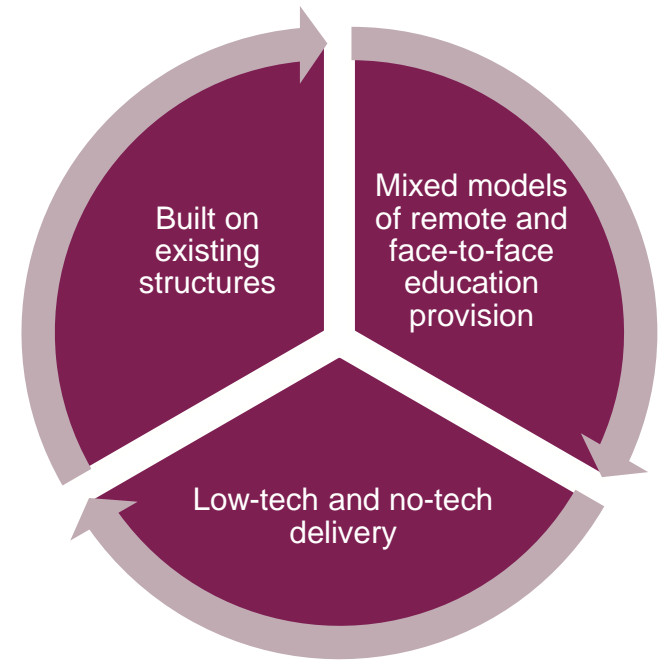

Source: Author's own.

This section therefore summarises the key lessons learned on EdTech approaches (including low-tech and no-tech approaches), and the role of the wider community and parents in supporting this learning.

Adjusting the curriculum can reduce the costs and time to create and implement remote learning content, which can enable a faster response to disruptions to education. Going forward, updating and adapting "core" subject remote learning materials could be a costand time-effective strategy and minimise learners' disruption to education.

In a number of countries, especially those that had not implemented large-scale remote learning programmes before the emergence of COVID-19, "core" subjects and foundational knowledge were prioritised in terms of the development and roll-out of remote learning 
approaches (World Bank, 2021a). These generally included reading, mathematics, and science. A qualitative research study from interviews with policymakers and education experts $^{4}$ found that this targeted approach was effective in reducing costs as well as the time required between content creation and dissemination (World Bank, 2021a, p. 42). However, the World Bank (2021a) highlighted the need for remote learning materials to focus not only on academic competencies, but competencies and skills required to effectively navigate the context causing disruption to education, including self-directed learning, socio-emotional skills, and wellbeing.

\section{EdTech}

Personalised learning software has demonstrated effectiveness in bridging learning gaps and addressing learning loss caused by disruptions to school in low-resource contexts (Dewan et al., 2021; Jordan et al., 2021; UNICEF Jordan, 2021).

A number of tablet- and smartphone-based apps have been developed to understand learners' level of proficiency in a subject, and tailor lessons and exercises to reflect the level identified (Jordan et al., 2021). In India, the Mindspark app improved numeracy scores by $38 \%$ over a period of four and a half months. In Malawi, the onecourse app addressed gender gaps in reading and mathematics amongst early grade students.

In the context of continued disruption to schooling due to emerging variants of COVID-19, embedding the key principles of accelerated and remedial learning into EdTech approaches is an important consideration to address the widening of learning inequity. However, this could have challenges for learners who do not have access to devices, the internet, or electricity.

Interactive radio instruction has been a common approach to ensuring the continuity of learning for underserved communities. However, it requires students to "take an active role in the learning process, for example answering questions or working in groups" to support effective learning (van Cappelle et al., 2021, p. 8). This learning environment may be difficult to foster at home with no facilitator. This highlights the importance of parental engagement and the need to support parents to help their children, and/or contact with teachers during school closures.

- In Bangladesh, 40-minute radio lessons were developed for primary-aged learners and were broadcasted across 16 radio stations from Sunday to Thursday, from 4.05pm (Bhattacharjee \& Shiblee, 2021). Over 200 of these lessons were interactive and allowed learners to listen to live sessions with teachers.

In India, only $2.7 \%$ of surveyed children across all grades that were enrolled in government and private schools reported that they used radio as a means to support their learning during school closures (van Cappelle et al., 2021, p. 8). Van Cappelle et al. (2021) note that static programming of radio- and television-broadcasted lessons could act as a barrier for adolescent learners in particular, who may have household chores or paid work

\footnotetext{
${ }^{4}$ From Uruguay, Estonia, Rwanda, Pakistan, Niger, Nepal, Mozambique, Malawi, Cameroon, Cambodia, and Afghanistan.
} 
responsibilities. This could be overcome, however, through repeat broadcasts, or making broadcasts available to download.

Remote learning that is supported through mobile phone texts and phone calls have proven benefit for attainment with greater gains for lower-achieving students (Angrist, Bergman et al., 2020; Angrist, de Barros et al., 2020). This suggests that the provision of support through mobile phones and other low-tech options can assist in closing equity gaps in learning.

A randomised controlled trial across 4,500 families with primary-aged children in Botswana measured the impact of a weekly SMS sent to parents, and a weekly SMS sent followed by a phone call over a four-week period (Angrist, Bergman et al., 2020). For both interventions, non-governmental organisation (NGO) staff working in partnership with the Ministry of Basic Education collected families' phone numbers from primary schools, and contacted parents to gauge interest on whether they were interested in receiving phone-based support for remote learning.

The weekly SMS contained a number of simple mathematics problems (see Figure 3), which was sent at the beginning of each week through a bulk SMS messaging platform (Angrist, Bergman et al. 2020, p. 5). The study found that in some cases, parents worked through the mathematics problems with their child, and in other cases parents passed on the message directly to their child. The estimated cost for this intervention over a four-week period was USD 3,200 (USD 2.13 per child).

For the second intervention, the weekly SMS was followed by a 15-20-minute phone call, which sought to provide support for learning, as well as encouraging motivation and accountability, and a measure of safeguarding by encouraging parents/caregivers to be present with their child during the phone call. The facilitator asked the parent to put the call on speaker and ensure the child was listening, therefore allowing both the parent and child to engage in learning together (Angrist, Bergman et al., 2020, p. 5). The facilitator answered any questions related to the mathematics problems in the SMSs, and provided a further mathematics problem to solve and practise (Figure 4 provides an example of the conversation). The study found that for approximately $37 \%$ of calls, facilitators only spoke with the parent/caregiver; however they used this time to help the parent to provide learning support on the SMS mathematics

Figure 3: An example of a mathematics problem sent by SMS to parents

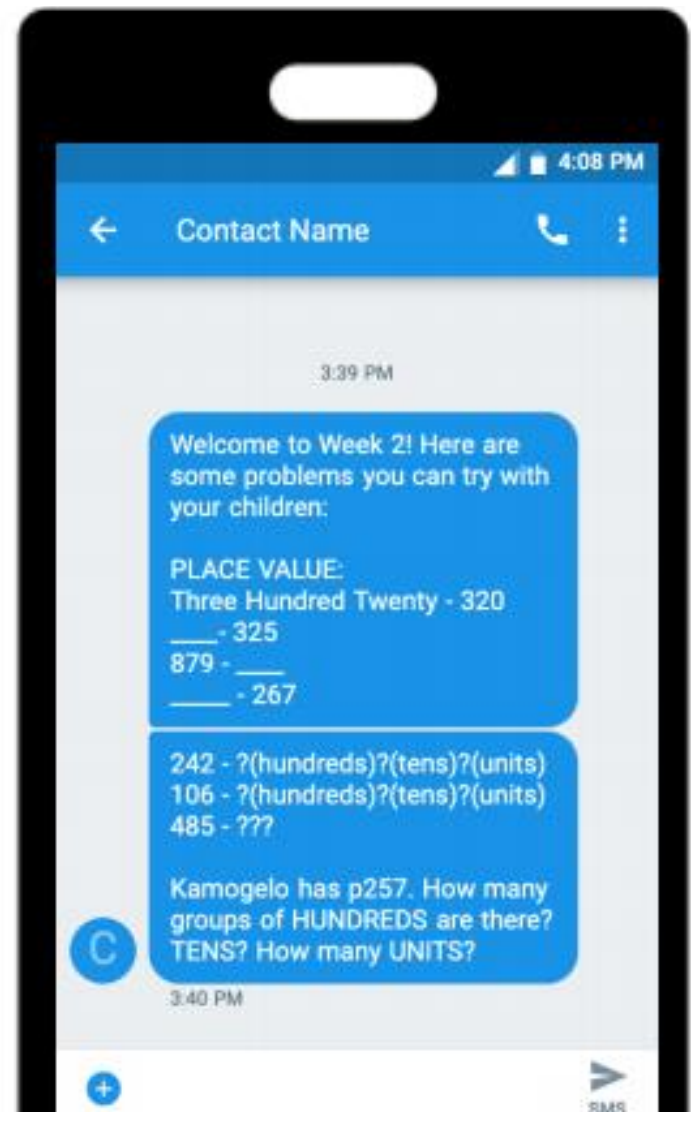

Source: Angrist, Bergman et al. (2020, p.6).

Reproduced with permission. 
problems. The estimated cost for this intervention over a four-week period was USD 17,800 (approximately USD 14 per child).

Both interventions resulted in a

significant positive effect on children's learning. Further, the study found that combining the SMS with a weekly follow-up call resulted in a $\mathbf{5 2 \%}$ reduction in innumeracy (Angrist, Bergman et al., 2020). The study also found higher parental engagement, and more accurate parental perceptions of their children's learning.

Similar examples of low-tech distance learning have demonstrated positive gains beyond academic learning. In India, a study found that adolescents' contact with teachers through SMSs improved their perception of learning (van Cappelle et al., 2021). Further, in Cambodia, the Ministry of Education worked with the Global

Figure 4: An example of a follow-up telephone call to parents and children Source: Angrist, Bergman et al. (2020, p. 6). Reproduced with permission. Hello Mma, my name is Kago from Young 1 ove.

I'm calling to make sure you received our SMS? Has your child, Sunshine attempted to solve any of the SMS problems? Please can we include your child in our call and put the phone on loud speaker so we can all hear the session. Sunshine, let's do a question together: I will share the number 284 how many hundreds, tens and units?

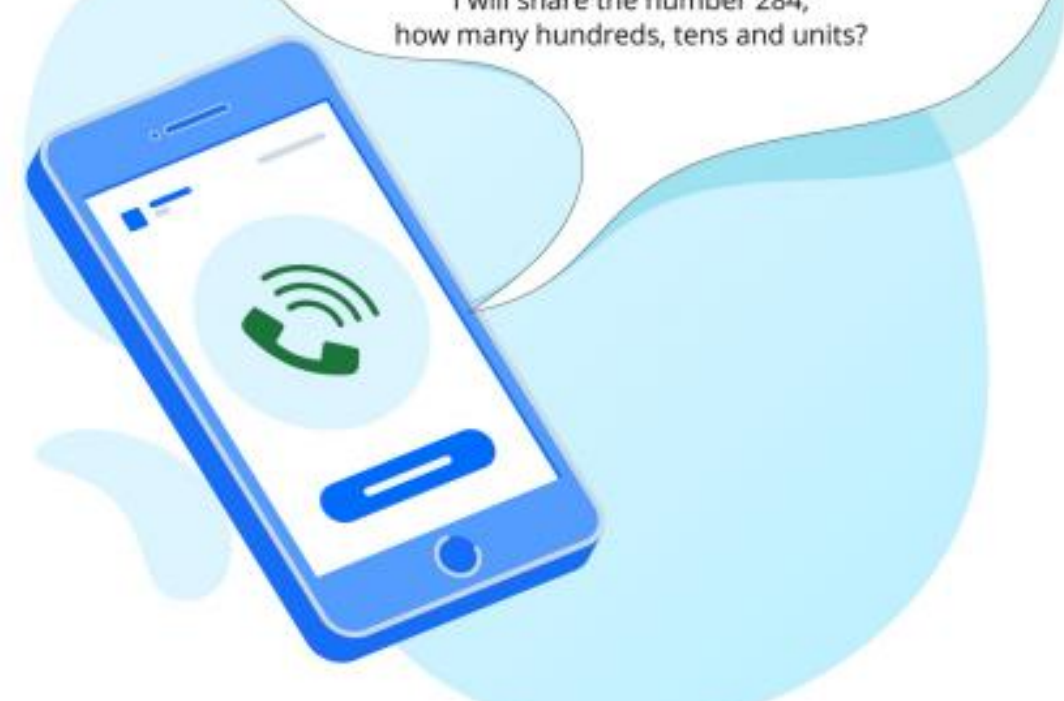

Partnership for Education

(GPE) to understand learners' access to technology and inform their response to COVID-19. GPE provided block grants to schools to purchase basic equipment and stationery, as well as paper-based learning materials for marginalised students. This was supported through SMSs and Telegram messages, as access to mobiles was relatively high (World Bank, 2021a). As with examples of teacher professional development cited earlier in this review, the use of existing, popular technologies, such as mobile phone apps and capabilities, demonstrates promise also for students' academic and non-academic learning outcomes.

A number of countries in the Asia-Pacific region have developed remote and distance learning options that included synchronous and asynchrous learning and engagement with teachers. However, these approaches were heavily dependent on access to internetenabled devices. Therefore, the experience of learning throughout school closures varied across income groups (UNESCO Asia et al., 2021, p. 46).

In Bangladesh, for example, learning materials were disseminated and live lessons broadcasted through popular social media platforms, including Facebook Live and YouTube. One Facebook page in particular (Ghore Boshe Shikhi) aired over 2,200 live lessons, which attracted over 10 million views. Classes covered academic lessons and subjects, as well as focusing on mental health and wellbeing and soft skills, including painting, web development, film-making, and game design (Bhattacharjee \& Shiblee, 2021, p. 27). 
Lessons from UNICEF's interventions in the Asia-Pacific region highlighted the need for stronger coordination and alignment amongst different interventions to support the continuation of learning and to enhance impact (Ackers, 2021), with application far beyond the region.

This includes training to teachers, parents, and learners on ICT skills and online safety, further training to teachers on remote learning pedagogy, mental health, and psycho-social support, and conducting remote assessments. This must be accompanied with a clear and coherent communication strategy to ensure uptake, and an adapted curriculum that reflects potential learning loss caused by disruption to schooling, and data to monitor and adjust.

Most importantly, however, UNICEF emphasised the need for alignment across all remote learning packages to effectively deliver the curriculum. For example, learning kits and selfstudy packs should supplement and support audiovisual broadcasts, which could then be further supported through SMS coverage as a forum for teachers' input and digital platforms to enable peer-to-peer discussion and access to additional educational resources (Ackers, 2021).

This is demonstrated somewhat in São Paulo, Brazil, where education authorities implemented a multi-modal remote learning programme. The programme was supported by strong communication campaigns (using adverts on television and social media to inform families and teachers about learning activities), specific actors that contacted families and learners who were out of reach, and frequent communication between teachers and the Education Secretary. As a result, the remote learning programme was accessed by a high percentage of learners (World Bank, 2021a).

\section{The role of parents, community members, and NGOs}

There is often an assumption that the remote element of education provision, whether implemented because of full school closure or as part of a blended model, involves technology. However, this is wrong. Examples of educational delivery that are built on mixed face-to-face and remote elements provided by parents, NGOs, and the wider community seemed to have been effective in ensuring the continuation of learning.

Research conducted before the pandemic demonstrated a strong positive association between children's home literacy environment (access to reading materials and support to use the materials) and their reading proficiency (Brossard et al., 2020). Therefore, interventions that supported parents' abilities to help their child learn were important as part of wider efforts to ensure the continuation of learning.

In low-resource contexts, this could involve encouraging parents to use local household materials to promote learning, especially for younger children and children with disabilities (Mcclain-Nhlapo et al., 2020). For example, beans and stones could be used to develop literacy skills (through using the object to create shapes of letters or words) and numeracy skills (counting, addition and subtraction). Encouraging learning through games has been found to be an effective means to support learning, although further research is required (Jordan et al., 2021).

In particular, supporting mothers who have not completed their education seemed an important focus, as in some contexts gender norms determined that mothers would support 
children's learning during school closures as part of their care responsibilities (Brossard et al., 2020; Kapur, 2020). For example, in Ethiopia, approximately $50 \%$ of primary caregivers had never been to school and could not read, and one third of primary caregivers had not completed primary school education (Mcclain-Nhlapo et al., 2020, p. 26).

Parents' accessibility to remote learning resources has therefore been raised as an important consideration to support children's continuation of learning and maintain learners' motivation to learn (Jordan et al., 2021). For example, in Sierra Leone, interventions used forums that are not dependent on text to communicate with parents in communities with low levels of literacy (Mcclain-Nhlapo et al., 2020). This included disseminating key information through radio, television, and mobile apps in areas with good access to these devices. However, in areas with limited access to technology, parents were sent information in picture format, including comic strips to explain how to run games to support early grade children's learning. Parents could also ask their children to read aloud to them, and support with pronunciation.

Examples of support that has been provided to parents include:

- In Indonesia, parents were supplied with entertainment and learning materials with the objective to enhance the quality of the home learning environment. This included audiovisual storybooks. An online platform, Sharing of Parents, was established to encourage peer-to-peer support and sharing of lessons amongst parents (MoECRT, 2021).

- In Kenya, the UK aid-funded Girls' Education Challenge programme developed guidance for parents to support their children's learning (McAleavy et al., 2021). This included posters, audio messages that were disseminated on social media (including WhatsApp), SMSs, household visits, and support from community health volunteers. A similar approach, Keep Kenya Learning, found that caregiver confidence to support children's learning increased, and access to educational resources on their phones increased (Kimathi et al., 2021). However, parents' belief that their knowledge and skills are relevant for their child's development did not change.

- Nepal, Somalia, Togo, and the Democratic People's Republic of Korea all reported in a joint survey commissioned by UNESCO, UNICEF, and the World Bank that teachers and/or principals made regular telephone calls to parents (McAleavy et al., 2021).

- In Mali, schools organised and facilitated regular "chat" sessions with learners, their parents, community leaders, and teachers (McAleavy et al., 2021).

Broader community actors have also been key in supporting parents to enable children's learning. In Rwanda, for example, community volunteers and local education activists developed materials to support parents through school closures, which included simple videos on helping children with disabilities, and audio messages that encouraged parents to keep positive when supporting children's learning (Mcclain-Nhlapo et al., 2020, p. 41). These actors also offered counsel and emotional support to parents through telephone conversations.

However, working with parents and community members requires effective leadership and coordination, including frequent consultation with key stakeholders to ensure the needs of learners and their families are met. In Bangladesh, for example, UNICEF strengthened 
partnerships with local NGOs to find solutions to continue to support learners in their communities (Coursac, 2021).

Findings from a desk-based study supported by semi-structured interviews with education stakeholders in Haiti note how NGOs implemented several innovative approaches that directly sought to address the gaps within the government's response to COVID-19 (Boothby et al., 2021). However, these interventions were often limited in scope and reach, which was hindered in part by the lack of coordination amongst the different actors and with government. This highlights the importance of effective leadership and coordination at a national and subnational level.

The Government of Haiti's response to COVID-19 was dependent on access to technology, including internet-enabled devices and television. However, a number of logistical challenges meant that broadcasting ended after a few weeks, and the content that had been televised could not be retrieved and re-aired (Boothby et al., 2021, p. 282). It is estimated that $1.7 \%$ of learners accessed the online learning platform; however, there are no available data on the reach of the televised lessons.

Success stories from the non-government response in Boothby et al. (2021) include:

- Schools liaising with parents who dropped off and picked up printed homework on a rotation system.

- Collaboration between two local NGOs and a university-based research centre developed three radio programmes which were broadcasted on various radio stations (including faith-based stations) and were accompanied by the distribution of 15,000 solar-powered radios (Boothby et al., 2021, p. 285). The broadcasts were in French and Creole, and included:

- Literacy lessons that were supplemented by a reading hour broadcast;

- A social and emotional learning programme for young children; and

- A programme that specifically targeted parent engagement.

- A local foundation that distributed basic mobile phones to 1,000 girls and arranged weekly catch ups to monitor and support their mental wellbeing, complemented by toll-free hotlines for girls to call to speak with either a nurse, teacher, or counsellor (Boothby et al., 2021, p. 286).

Elsewhere, liaison with non-academic professionals, including mental health support, has been successful. In Lebanon, where there is a high proliferation of internet-enabled devices and access to the internet, WhatsApp was used to send videos and audio messages to provide parents with content and advice to support their children's learning (Mcclain-Nhlapo et al., 2020, p. 40). An inclusive schools' programme pilot supported head teachers to coordinate with school staff, therapists, other professionals, and parents to ensure that remote learning is inclusive for all learners. 


\section{Reaching the most marginalised}

The importance of low-tech and no-tech approaches to remote learning is emphasised in the context of marginalised learners, and therefore a no-tech safety net cannot be underestimated.

From a UNICEF survey covering 44 countries, the most frequent response to how actors within these countries were supporting marginalised groups, reported by 28 countries, was sending physical packages of learning materials to children who do not have access to radio, television, or internet-enabled devices and the internet (UNICEF, 2021d). This is important to ensure retainment and engagement with marginalised learners, and therefore mitigate the risk of dropout, as highlighted within several ministry of education strategies:

- In Ecuador, the Education Continuity Plan puts supporting the most vulnerable at the centre and outlines that school retention is one of the most important outcomes during the emergency period (MoE, 2020).

- The Bangladesh plan outlines using differentiated approaches including non-formal education, proactive tracking of at-risk students, as well as social media campaigns to promote the importance of home learning and, as schools reopen, returning to school (MoPME \& MoE, 2020).

Beyond education-specific interventions, the provision of basic humanitarian support for families in crisis, including food and key staples, was critical to support the most marginalised. More generally, basic support is especially important to protect girls' learning outcomes, as economic uncertainty has been found to increase the likelihood of coping strategies to restrict women and girls' food intake (as discriminatory gender norms in some contexts prioritise men's health and nutrition (Kapur, 2020). But it is also an important consideration in contexts that offered school feeding programmes to ensure that learners could continue to focus on their education.

- In India, state authorities delivered milk, fruit, and vegetables to children's homes with their worksheets (Coursac, 2021; UNESCO Asia et al., 2021, p. 24).

- In Brazil, the government distributed food baskets to disadvantaged families (Niemczyk et al., 2021, p. 178).

- In South Sudan, a UK aid-funded programme provided cash transfers to marginalised learners, including girls, to ensure that their basic needs are met during the period of school closures (Mcclain-Nhlapo et al., 2020, p. 37).

- In Algeria, working mothers who have children with disabilities were provided with paid leave (Mcclain-Nhlapo et al., 2020, p. 70).

Financial support to continue learning was also important for learners from poor socioeconomic backgrounds.

- In Indonesia, the Ministry of Education, Culture, Research and Technology (MoECRT) provided financial support for disadvantaged learners to access tuition assistance, through an Indonesian Smart Card scheme (MoECRT, 2021).

- The MoECRT in Indonesia also distributed an internet data quota to over two million recipients to support remote learning, which included students (MoECRT, 2021).

- Marginalised adolescent girls within refugee camps in Northern Kenya were provided with conditional cash transfers to address financial barriers to their education 
(UNICEF, 2021a, p. 39). Cash transfers were provided to 20,000 girls within femaleheaded households, through multiple disbursement platforms including mobile money. As a result, attendance rates amongst the targeted cohorts increased by $70 \%$, and these girls achieved a $90 \%$ graduation rate to the next grade.

For many children with disabilities, COVID-19 has exacerbated social and educational isolation. Many remote learning approaches adopted by countries were not accessible to learners with additional needs, including those with visual and hearing impairments (Mcclain-Nhlapo et al., 2020). This remains a key challenge.

Globally, there is differential access to different technologies, including radios, televisions, mobile phones, and internet-enabled devices. However, an online survey issued to parents of children with disabilities during the period of school closures highlighted mixed attitudes to the usability and usefulness of technology to support their child's learning (Mcclain-Nhlapo et al., 2020, p. 21). Accessibility of remote learning approaches was also dependent on:

- Access to the internet and data packages;

- Parent or caregivers' ability to provide support;

- Language of instruction (in many countries sign language is not recognised as an official language);

- A lack of individualised learning and support for children with disabilities; and

- Challenges in procuring and distributing large volumes of items (including tech) in emergency contexts.

However, there were a number of examples that can be learned from to inform the scale of future interventions, although more research is needed to better understand their impact.

Approximately 60 countries adopted social protection measures for persons with disabilities, and 18 specifically adopted measures to target children with disabilities (Mcclain-Nhlapo et al., 2020). An important consideration for reaching children with disabilities to continue learning is the adoption of Universal Design for Learning (UDL), which acknowledges that all learners are different, and therefore teaching and learning should use a variety of methods to support all learners' needs. This was demonstrated in a variety of contexts.

In 2014, the Government of Bangladesh launched a new initiative to provide learners with print and learning disabilities access to virtual reading, called Accessible Reading Materials (ARM), through the provision of low-cost assistive reading devices (Bhattacharjee \& Shiblee, 2021). In response to COVID-19 and subsequent school closures, the government converted all grade 1-12 textbooks and made these available through ARM. This was complemented by the provision of accessible dictionaries and teacher training on UDL. The benefits of the intervention during school closures included a reported increase in learning independence and improvements in visually impaired learners' Higher Secondary Exam results.

However, it should be acknowledged that, unlike other initiatives implemented in response to COVID-19 to reach children with disabilities, the children who benefited from ARM during the pandemic had prior experience of using these accessible materials and assistive technologies. The benefit of the ARM initiative can therefore be seen as an expansion of children's access to learning during school closures (Bhattacharjee \& Shiblee, 2021).

In addition to this: 
- In Peru, televised lessons were supported with sign language interpreters, radio lessons were delivered in nine different languages, and online-based learning materials were adapted specifically for learners with additional needs (World Bank, 2021a).

- In Rwanda, sign language interpretation was included in televised lessons, and Braille learning resources were developed to support radio lessons in English, Kinyarwanda, and mathematics (Mcclain-Nhlapo et al., 2020, p. 20). However, few learners received copies of these resources (168 across the country at the time of publication). In addition, digital supplementary readers and textbooks were developed and distributed through a variety of channels.

\section{Supporting parents who became full-time carers for a child with disabilities and educators when schools closed was crucial to maintain children's engagement with learning.}

In Rwanda, the Rwanda Education Board disseminated guidance to parents with children with disabilities on how to support their child during school closures (Mcclain-Nhlapo et al., 2020 , p. 20). This included contact by head teachers and community volunteers through home visits or telephone calls to provide support and monitor children's interaction and engagement with learning materials, and mobilising support from young people with disabilities to support families.

In some contexts, EdTech approaches to support the continuation of learning during school closures risked exacerbating existing gender, digital, and financial divisions and inequity in education (Oulo et al., 2021). However, radio lessons and paper-based resources, supported by facilitated reading camps, have been found to support adolescent girls' learning outcomes in reading and mathematics (Amenya et al., 2021).

It was estimated that boys were 1.5 times more likely to own a phone than their female counterparts and one third more likely to access the internet, before the onset of COVID-19 (Oulo et al., 2021, p. 3).

This assessment is generally supported by a survey issued in May/June 2020, which found that most marginalised girls in Kenya did not have access to television or radio lessons during the period of school closures. To mitigate the anticipated impacts of the pandemic on girls' education outcomes, including poor performance and dropout, in part due to increases in domestic chores and limited access to technology, the UK aid-funded Wasichana Wetu Wafaulu programme worked with community health volunteers ( $\mathrm{CHVs}$ ) to establish reading camps (Amenya et al., 2021). These camps provided a form of peer learning in Arid and Semi-Arid Lands (ASAL), where up to five girls from grades 6 and 7 met to engage in learning activities, and were facilitated by remedial teachers. Reading camps were further supported by camp mentors, who "were mainly secondary and university level students, [and] provided more targeted facilitation focusing on areas such [as] timetable development, time management, values, adolescent sexuality, and reproductive health" (Amenya et al., 2021, p. 11). Groups met up to five times per week from $8 \mathrm{am}$ to $12 \mathrm{pm}$, and CHVs monitored and tracked girls' attendance. When girls did not attend the reading camps, the CHVs made household visits. This was supported by community messaging activities to raise awareness of the importance of girls continuing their studies, including through attending the reading camps.

Mixed-methods research into girls' learning experiences identified the potential impact for peer-based learning. The research found that attendance of the reading camps, paper-based 
learning resources, and listening to radio lessons in groups were associated with higher performance in reading and mathematics (Amenya et al., 2021). In addition, parents released girls from their household responsibilities to attend the reading camps and complete their homework, and participation in reading camps partially offset the barriers to learning that some girls experienced due to living with illiterate household members. Lastly, participation in the reading camps and group discussions reportedly benefited girls' self-confidence, motivation for learning, and discipline.

In Burkina Faso, a similar approach was adopted to support girls during school closures (UNICEF, 2020). Female community coaches were "beacons of hope" for girls, by providing advice and support in menstrual hygiene management and life skills, and raised awareness within the community of the importance of girls' learning (UNICEF, 2020, p. 2). Often, the coaches were internally displaced persons (IDPs) and were educated, and this encouraged girls' prioritisation of their studies, which was especially impactful in communities with a limited number of qualified teachers. This was further complemented by women's groups, which proactively identified and supported girls at risk of school dropout.

A number of publications highlight the importance of providing psycho-social support to marginalised girls (Naylor et al., 2021; Oulo et al., 2021; UNICEF, 2021a). In addition, interventions that support girls through online platforms and internet-enabled devices must also include safeguarding measures to protect them from harm and online abuse (Naylor et al., 2021).

\section{Low-cost technology, including WhatsApp, was an important tool in maintaining contact with marginalised girls and ensuring their continuity of learning.}

In Dzaleka refugee camp in Malawi, teachers were trained in a variety of remote learning approaches (including radio, social media, and other online platforms), and secondary school-aged girls were provided with smartphones and data bundles (UNICEF, 2021a, p. 24). The Jesuit Refugee Service (JRS) installed solar infrastructure in a local office, which provided "a free and safe place for girls to charge their laptops and phones and study as needed" (UNICEF, 2021a, p. 24). However, the upfront cost per girl was USD 195, with a monthly running cost of USD 30 per girl. Radios were also procured and distributed in the camp to enable access to radio lessons. Homework was issued and feedback was collected via WhatsApp, and the JRS convened frequent "listening sessions" for girls, which addressed issues including early marriage, GBV, and household responsibilities. In response to concerns raised in these listening sessions, girls were given access to social workers, counsellors, and a mother group. This provided girls with continuity of learning during school closures.

In Zimbabwe, a UK aid-funded programme provided teachers and community volunteers with a small data bundle and organised these individuals with school-aged girls into WhatsApp groups, which acted as a forum to share materials and learning activities (ZwierMarongedza, 2021). Approximately 6,000 girls were supported. WhatsApp was also used by the community volunteers as an alert system to at-risk girls, and by the programme to communicate with religious and community-based leaders to highlight the key issues facing adolescent girls and their access to education (see https://en.unesco.org/news/educationthrough-whatsapp-keeping-girls-learning-and-safe-during-lockdown-zimbabwe for an example). 


\section{References}

ACAPS. (2020). Education and child protection challenges in Eastern DRC: Impact of COVID-19, conflict and policy reform. ACAPS.

https://reliefweb.int/sites/reliefweb.int/files/resources/20201019_acaps_covid-

19_thematic_series_on_education_drc_eastern_provinces.pdf

Ackers, J. (2021, 27 July). A proposed response to the recent waves of COVID-19 on education in Asia. Global Education Summit: Financing GPE 2021-2025: Side Events.

https://apa.sdg4education2030.org/sites/apa.sdg4education2030.org/files/2021-

07/3_Session\%201_Plenary_A\%20proposed\%20response\%20to\%20COVID-

19_Jim\%20Ackers.pdf

Amenya, D., Fitzpatrick, R., Mvungu, E. N., Naylor, R., Page, E., \& Riggall, A. (2021). The power of girls' reading camps: Exploring the impact of radio lessons, peer learning and targeted paperbased resources on girls' remote learning in Kenya. EdTech Hub.

https://doi.org/10.5281/ZENODO.4923094

Andrabi, T., Daniels, B., \& Das, J. (2020). Human capital accumulation and disasters: Evidence from the Pakistan earthquake of 2005 (RISE Working Paper No. 20/039). Research on Improving Systems of Education (RISE). https://doi.org/10.35489/BSG-RISEWP_2020/039

Angrist, N., Bergman, P., Brewster, C., \& Matsheng, M. (2020). Stemming learning loss during the pandemic: A rapid randomized trial of a low-tech intervention in Botswana (CSAE Working Paper WPS/2020-13). Centre for the Study of African Economies, University of Oxford.

https://ora.ox.ac.uk/objects/uuid:0c31bf52-fd39-41ac-8570-e07e6ea78fc4

Angrist, N., de Barros, A., Bhula, R., Chakera, S., Cummiskey, C., DeStefano, J., Floretta, J., Kaffenberger, M., Piper, B., \& Stern, J. (2020). Building back better to avert a learning catastrophe: Estimating learning loss from COVID-19 school shutdowns in Africa and facilitating short-term and long-term learning recovery. International Journal of Educational Development, 84. https://doi.org/10.1016/j.ijedudev.2021.102397

Banerji, R. (2020, 6 July). Learning "loss" and learning "gain" in primary school years: What do we know from India that can help us think forward in the COVID-19 crisis? (Insight Note). Research on Improving Systems of Education (RISE). https://doi.org/10.35489/BSG-RISERI_2020/019

Belafi, C., \& Kaffenberger, M. (2020). Children in school but not learning, for different strategies to mitigate the Covid-19 shock. In: Data visualisations: Estimating COVID-19 related learning losses and effects of mitigation. Research on Improving Systems of Education (RISE). https://riseprogramme.org/tools/simulating-learning\#vis1

Bhattacharjee, V., \& Shiblee, S. M. (2021). COVID 19, technology-based education and disability: The case of Bangladesh. Emerging practices in inclusive digital learning for students with disabilities. UNESCO.

https://unesdoc.unesco.org/ark:/48223/pf0000377665/PDF/377665eng.pdf.multi

Boothby, N., Hart, A., Chandler, H., \& Dupuy, D. (2021). Leveraging community-based innovations during COVID-19 to strengthen the Haitian school system. Perspectives in Education, 39(1), 281-290. https://doi.org/10.18820/2519593X/pie.v39.i1.17 
Brossard, M., Cardoso, M., Kamei, A., Mishra, S., Mizunoya, S., \& Reuge, N. (2020). Parental engagement in children's learning. Insights for remote learning response during COVID-19 (Innocenti Research Brief). UNICEF Office of Research - Innocenti. https://www.unicefirc.org/publications/pdf/IRB\%202020-09.pdf

Cilliers, J., Fleisch, B., Kotzé, J., Mohohlwane, N., Taylor, S., \& Thulare, T. (2021). Can virtual replace in-person coaching? Experimental evidence on teacher professional development and student learning in South Africa (RISE Working Paper 20/050). Research on Improving Systems of Education. https://doi.org/10.35489/BSG-RISE-WP_2020/050

Comunidad Atenea. (n.d.). Comunidad Atenea. https://comunidadatenea.org/

Coursac, I. (2021, July 27). Challenges and responses to COVID: Country specific approaches in South Asia around distance learning and remediation. Global Education Summit: Financing GPE 2021-2025: Side Events.

https://apa.sdg4education2030.org/sites/apa.sdg4education2030.org/files/2021-

07/5A_Session2_Breakout_Group\%20B_Ivan\%20Coursac.pdf

Dewan, P., Carnelli, M., Tubio, M. L., Pontuschka, R., \& Tsuruyama, E. (2021, 19 May). Reimagining digital learning: Lessons from the Learning Passport in Timor-Leste. UNICEF. https://blogs.unicef.org/evidence-for-action/reimagining-digital-learning-lessons-from-thelearning-passport-in-timor-leste/

Diamond, G. (2021, 17 March). Is WhatsApp an unsung hero in the COVID-19 education crisis? Perspective. https://www.ungei.org/blog-post/whatsapp-unsung-hero-covid-19-education-crisis

EdTech Hub. (2020). The effect of Covid-19 on education in Africa and its implications for the use of technology: A survey of the experience and opinions of educators and technology specialists. https://inee.org/system/files/resources/The_effect_of_Covid-

19_on_Education_in_Africa.pdf

Enabel, Ministry of Education and Sports, \& Teacher Training Education Project. (2020). NTCs leading in crisis, reimagining the future: Concluding report of Teachers' Day for the NTCs, 8th October 2020. https://teachertaskforce.org/sites/default/files/2020-

11/Teacher_Education_Digital_Resources_2020.pdf

Gordon, M. (2020). The hidden impact of Covid-19 on children's education. Save the Children. https://inee.org/system/files/resources/the_hidden_impact_of_covid-19_on_child_education.pdf

Hallgarten, J. (2020). Evidence on efforts to mitigate the negative educational impact of past disease outbreaks. (K4D Helpdesk Report No. 793). Education Development Trust.

https://opendocs.ids.ac.uk/opendocs/handle/20.500.12413/15202

Hossain, M. (2021). Unequal experience of COVID-induced remote schooling in four developing countries. International Journal of Educational Development, 85.

https://doi.org/10.1016/j.ijedudev.2021.102446

INEE (Inter-Agency Network for Education in Emergencies). (2018). Psychosocial support: Facilitating psychosocial wellbeing and social and emotional learning (Guidance Note). https://resourcecentre.savethechildren.net/node/10600/pdf/inee_guidance_note_on_psychosocia I_support_eng_v2_0.pdf 
International Task Force on Teachers for Education 2030. (2021). Teaching on the front line: National teacher responses to the COVID-19 crisis. UNESCO.

https://teachertaskforce.org/knowledge-hub/teaching-front-line-national-teacher-responses-covid19-crisis

International Task Force on Teachers for Education 2030, UNESCO, \& ILO. (2020). Supporting teachers in back-to-school efforts: A toolkit for school leaders.

https://teachertaskforce.org/sites/default/files/2020-

09/Supporting\%20teachers\%20in\%20back\%20to\%20school\%20efforts_second\%20edition.pdf

Jenkins, R., \& Banerji, R. (2021, 3 March). How can formative assessment foster learning as schools reopen? UNICEF Connect: Evidence for Action. https://blogs.unicef.org/evidence-foraction/how-can-assessment-foster-learning-as-schools-reopen/

Johns Hopkins University, World Bank, \& UNICEF. (2021). Covid-19 global education recovery tracker. https://www.covideducationrecovery.global/stories/2021-09-23-gert-data-points/

Jordan, K., David, R., Phillips, T., \& Pellini, A. (2021). Education during the COVID-19: Crisis opportunities and constraints of using EdTech in low-income countries. Revista de Educación a Distancia (RED), 21(65). https://doi.org/10.6018/red.453621

Kaffenberger, M. (2021). Modelling the long-run learning impact of the Covid-19 learning shock: Actions to (more than) mitigate loss. International Journal of Educational Development, 81, 102326. https://doi.org/10.1016/j.ijedudev.2020.102326

Kapur, N. (2020). School closures in the context of COVID-19: An inequity impact assessment of Primary 2 and 3 pupils in Rwanda. Building Learning Foundations.

http://buildinglearningfoundations.rw/wp-content/uploads/2021/04/Impact-assessmentRwanda.pdf

Kimathi, D., El-Serafy, Y., Plaut, D., \& Kaye, T. (2021, 16 July). Keeping Kenya learning: The importance of caregiver engagement in supporting learning beyond the classroom. EdTech Hub. https://edtechhub.org/2021/07/16/keeping-kenya-learning-the-importance-of-caregiverengagement-in-supporting-learning-beyond-the-classroom/

Laverde, M. (2021). COVID 19, technology-based education and disability: The case of Colombia. Emerging practices in inclusive digital learning for students with disabilities. UNESCO. https://unesdoc.unesco.org/ark:/48223/pf0000377773/PDF/377773eng.pdf.multi

McAleavy, T., Riggall, A., \& Korin, A. (2021). Learning renewed: Ten lessons from the pandemic. Education Development Trust.

https://www.educationdevelopmenttrust.com/EducationDevelopmentTrust/files/aa/aaa405c0e492-4f74-87e3-e79f09913e9f.pdf

Mcclain-Nhlapo, C. V., Ruchi, K. S., Martin, A. H., Alasuutari, H. K., Baboo, N., Cameron, S. J., Hayes, A. E., Johnstone, C., Maladwala, A., McGeown, J., Richler, D., Singal, N., \& Tucker, M. (2020). Pivoting to inclusion: Leveraging lessons from the COVID-19 crisis for learners with disabilities (English) (Working Paper No. 151213). World Bank. https://documents. worldbank.org/en/publication/documentsreports/documentdetail/777641595915675088/pivoting-to-inclusion-leveraging-lessons-from-thecovid-19-crisis-for-learners-with-disabilities 
MoE (Ministry of Education, Ecuador). (2020). Juntos aprendemos y nos cuidamos. Plan de continuidad educative, permanencia escolar y uso progresivo de las instalaciones educativas. [Together we learn and take care of ourselves. Plan of educational continuity, school permanence and progressive use of educational facilities.] https://educacion.gob.ec/wpcontent/uploads/downloads/2020/08/Guia-para-la-alternancia-entre-la-educacion-casa-y-laeducacion-en-la-escuela.pdf

MoECRT (Indonesia Ministry of Education, Culture, Research, and Technology). (2021, 27 July). Sharing from Indonesia: Education service provision during pandemic. https://apa.sdg4education2030.org/sites/apa.sdg4education2030.org/files/202107/6B_Session2_Breakout_Country\%20Case\%20Studies_Indonesia.pdf

MoPME \& MoE (Ministry of Primary and Mass Education, \& Ministry of Education). (2020). Covid-19 Response and Recovery Plan - Education Sector. Government of the People's Republic of Bangladesh.

https://planipolis.iiep.unesco.org/sites/default/files/ressources/bangladesh_moe_covid_19_respo nse_and_recovery_plan.pdf

Mwabe, J., Austrian, K., \& Macharia, S. (2021). Promises to keep: Impact of Covid-19 on adolescents in Kenya. Population Council.

https://www.popcouncil.org/uploads/pdfs/2021PGY_ImpactCovidAdolKenya.pdf

Naylor, R., Hine, S., \& West, A. (2021). Mind the gap: The state of girls' education in crisis and conflict. Inter-agency Network for Education in Emergencies. https://inee.org/resources/mindgap-state-girls-education-crisis-and-conflict

Niemczyk, E. K., de Beer, Z. L., \& Steyn, H. J. (2021). The challenges posed by COVID-19 to the BRICS education systems: Lessons to be learnt. Perspectives in Education, 39(1).

https://doi.org/10.18820/2519593X/pie.v39.i1.11

Oulo, B., Sidle, A. A., Kintzi, K., Mwangi, M., \& Akello, I. (2021). Understanding the barriers to girls' school return: Girls' voices from the frontline of the COVID-19 pandemic in East Africa (AMPLIFY COVID-19 Research Brief). AMPLIFY Girls.

https://static1.squarespace.com/static/5c86d4507fdcb8fc46e7d529/t/60d4fb74d835f0200cdea52 1/1624570756879/Understanding+the+Barriers+to+Girls\%27+School+Return-

+Girls\%27+Voices+from+the+frontline+of+the+COVID-19+Pandemic+in+East+Africa.++.pdf

Page, E., Leonard-Kane, R., Kashefpakdel, E., Riggall, A., \& Guerriero, S. (2021). Learning loss, learning gains and wellbeing: A rapid evidence assessment. Education Development Trust. https://www.educationdevelopmenttrust.com/EducationDevelopmentTrust/files/20/201258b498ab-415a-b0da-f33d5cf8688d.pdf

Peepul. (n.d.). Peepul India. https://www.peepulindia.org/

Rahman, A. F., Khan, F. S., \& Lone, T. (2021). Lessons learned: COVID-19 education response for non-formal education in Sindh, Pakistan. Oxfod Policy Management.

https://www.opml.co.uk/files/Publications/a2758-supporting-primary-education-sindh-sensa/opmsensa-lessons-learned-report-web.pdf?noredirect=1

Save the Children. (2020). Safe schools: Teacher professional development. Module 2: Teacher well-being. Save the Children. https://resourcecentre.savethechildren.net/library/safe-backschool-practitioners-guide 
UNESCO. (n.d.). Global monitoring of school closures. In: Education: From Disruption to Recovery. UNESCO. https://en.unesco.org/covid19/educationresponse\#schoolclosures

UNESCO Asia, Pacific Regional Bureau for Education, \& UNESCO Institute for Statistics. (2021). School closures and regional policies to mitigate learning loss due to COVID-19: A focus on the Asia-Pacific.

http://uis.unesco.org/sites/default/files/documents/school_closures_and_regional_policies_to_mit igate_learning_losses_in_asia_pacific.pdf

UNESCO, UNICEF, World Bank, \& OECD. (2021). What's next? Lessons on education recovery: Findings from a survey of ministries of education amid the Covid-19 pandemic (Survey on National Education Responses to COVID-19 School Closures, Round 3.).

http://uis.unesco.org/sites/default/files/documents/lessons_on_education_recovery.pdf

UNICEF. (2020). Burkina Faso - Opening schools up better (UNICEF Education COVID-19 Case Study). https://aa9276f9-f487-45a2-a3e7-

8f4a61a0745d.usrfiles.com/ugd/aa9276_907976fcc47a4a73b0ac78a084a1f46b.pdf

UNICEF. (2021a). Reimagining girls' education: Solutions to keep girls learning in emergencies.

UNICEF. https://www.unicef.org/reports/reimagining-girls-education

UNICEF. (2021b). Somalia - Integrated school reopening (UNICEF Education \& COVID-19 Case Study). https://545bf665-9f6a-4acf-941f-

6d7463c8d5b8.usrfiles.com/ugd/545bf6_1bf8393b9d3e46bebc8c072ceef4f0dc.pdf

UNICEF. (2021c). Sri Lanka - Integrated school reopening (UNICEF Education COVID-19 Case Study). https://545bf665-9f6a-4acf-941f-

6d7463c8d5b8.usrfiles.com/ugd/545bf6_254e7f680c62403ebabbca6fe7415023.pdf

UNICEF. (2021d, May). Tracking the situation of children during COVID-19. UNICEF.

https://data.unicef.org/resources/rapid-situation-tracking-Covid-19-socioeconomic-impacts-dataviz/

UNICEF. (2021e). Brazil - Preparing for an integrated school reopening to address children's comprehensive needs (UNICEF Education \& COVID-19 Case Study). https://b2315f08-09cf4a7a-b224-5b9df6403e51.usrfiles.com/ugd/b2315f_ceb9786382eb413fb0ef46b3343fbbf2.pdf

UNICEF. (2021f). Chad - Accelerating school reopening in Chad using an integrated approach (UNICEF Education COVID-19 Case Study). https://b2315f08-09cf-4a7a-b2245b9df6403e51.usrfiles.com/ugd/b2315f_9e33a52f153344c281795c470902a347.pdf

UNICEF. (2021g). China - Leveraging UNICEF's multisectoral expertise for school reopening (UNICEF Education COVID-19 Case Study). https://b2315f08-09cf-4a7a-b2245b9df6403e51.usrfiles.com/ugd/b2315f_b130cca7d723472887d87664367fb2cd.pdf

UNICEF Jordan. (2021, 22 February). Jordan - Unleashing the potential of youth through the Youth Learning Passport (UNICEF Education Reimagine Education Case Study).

https://www.unicef.org/media/100716/file/Case\%20study\%20Jordan\%20Learning\%20Passport\% 20.pdf

van Cappelle, F., Chopra, V., Ackers, J., \& Gochyyev, P. (2021). An analysis of the reach and effectiveness of distance learning in India during school closures due to COVID-19. International Journal of Educational Development, 85, 102439. https://doi.org/10.1016/j.jijedudev.2021.102439 
Varkey Foundation. (2020, 14 October). TikTok and Varkey Foundation seek to enhance teaching practices in Latin America. Varkey Foundation.

https://www.varkeyfoundation.org/es/opini\%C3\%B3n/tiktok-and-varkey-foundation-seek-toenhance-teaching-practices-in-latin-america/

World Bank. (2018). Learning to realize education's promise (World Development Report 2018). https://doi.org/10.1596/978-1-4648-1096-1

World Bank. (2020). The World Bank's education response to COVID-19. https://thedocs.worldbank.org/en/doc/4879716083266403550090022020/original/ExternalWBEDUResponsetoCOVIDDec15FINAL.pdf

World Bank. (2021a). Exploring the deployment, perceived effectiveness, and monitoring of remote and remedial learning. World Bank.

https://openknowledge.worldbank.org/handle/10986/36061

World Bank. (2021b, 22 January). Urgent, effective action required to quell the impact of COVID19 on education worldwide. World Bank. https://www.worldbank.org/en/news/immersivestory/2021/01/22/urgent-effective-action-required-to-quell-the-impact-of-covid-19-on-educationworldwide

Yorke, L., Rose, P., Hagos, B., \& Woldehanna, T. (2020). The effects of COVID-19 on primary education in Ethiopia: Perspectives of school principals and teachers (Research and Policy Paper No. 20/10). REAL Centre, University of Cambridge, UK.

https://www.educ.cam.ac.uk/centres/real/publications/Effects\%20of\%20COVID19\%20on\%20principals\%20and\%20teachers_Ethiopia.pdf

Yorke, L., Rose, P., Woldenhanna, T., \& Hailu, B. H. (2021). Primary school-level responses to the COVID-19 pandemic in Ethiopia: Evidence from phone surveys of school principals and teachers. Perpectives in Education, 39(1), 189-206.

https://doi.org/10.18820/2519593X/pie.v39.i1.12

Zwier-Marongedza, J. (2021, 16 March). Education through WhatsApp: Keeping girls learning and safe during lockdown in Zimbabwe. UNESCO. https://en.unesco.org/news/educationthrough-whatsapp-keeping-girls-learning-and-safe-during-lockdown-zimbabwe

\section{Key websites}

- Tracking the situation of children during COVID-19: https://data.unicef.org/resources/rapid-situation-tracking-Covid-19-socioeconomicimpacts-data-viz/

- Global monitoring of school closures caused by COVID-19: http://covid19.uis.unesco.org/global-monitoring-school-closures-covid19/countrydashboard/

- Education: From disruption to recovery: https://en.unesco.org/covid19/educationresponse\#schoolclosures 